\title{
Mean (Standard Deviation) or Mean (Standard Error of Mean): Time to Ponder
}

\author{
Pankaj Kumar Garg • Debajyoti Mohanty
}

Published online: 30 November 2012

(C) Société Internationale de Chirurgie 2012

We read the article titled Antibiotics as First-line Therapy for Acute Appendicitis: Evidence for a Change in Clinical Practice by Hansson et al. [1] with great interest. The authors presented the quantitative data as mean \pm standard error of mean (SEM) in Table 1 , and not as mean \pm standard deviation (SD). The misconception about the use of SEM in descriptive statistics continues to prevail, even in leading medical journals. We wish to clarify these two terms. Normally distributed quantitative data should be summarized as mean (SD). Here, the SD refers to the variation in the values of the variable within the sample. The larger the SD, the greater the variability within the sample. When we report a sample mean, say weight, we wish to know the mean weight of the population from which we have taken the sample. The sample mean will vary every time we take a new sample from a given population. Confidence interval (CI) gives a range to show how much this sample mean weight would vary if we keep on taking samples. The SEM is used to derive the confidence interval [2]. Therefore; the SEM gives us an idea of the accuracy of the mean. As SEM is always smaller than $\mathrm{SD}$ ( $\mathrm{SEM}=\mathrm{SD} /$ (square root of sample size), many authors use SEM to hide a large SD and thus imply that their observations are more accurate [3]. One may also say that showing the SEM with the mean will help them to indicate the accuracy of the sample mean; however, CI is the right statistical tool to accomplish this. We believe that if authors adhere to basic statistical principals, the problem of misuse of SEM can easily be avoided.

\section{References}

1. Hansson J, Körner U, Ludwigs K et al (2012) Antibiotics as firstline therapy for acute appendicitis: evidence for a change in clinical practice. World J Surg 36:2028-2036. doi:10.1007/s00268-0121641-x

2. Choudhary D, Garg PK (2012) $95 \%$ Confidence interval: a misunderstood statistical tool. Indian J Surg (in press). doi:10. 1007/s12262-012-0555-Z

3. Jaykaran (2010) Mean \pm SEM or Mean (SD)? Indian J Pharmacol 42:329
P. K. Garg $(\bowtie) \cdot$ D. Mohanty

Department of Surgery and Medical Education Unit, University College of Medical Sciences and Guru Teg Bahadur Hospital, University of Delhi, Delhi 110095, India

e-mail: dr.pankajgarg@gmail.com

\section{P. K. Garg}

Department of Surgery, University College of Medical Sciences and Guru Teg Bahadur Hospital, Dilshad Garden, Delhi 110095, India 